
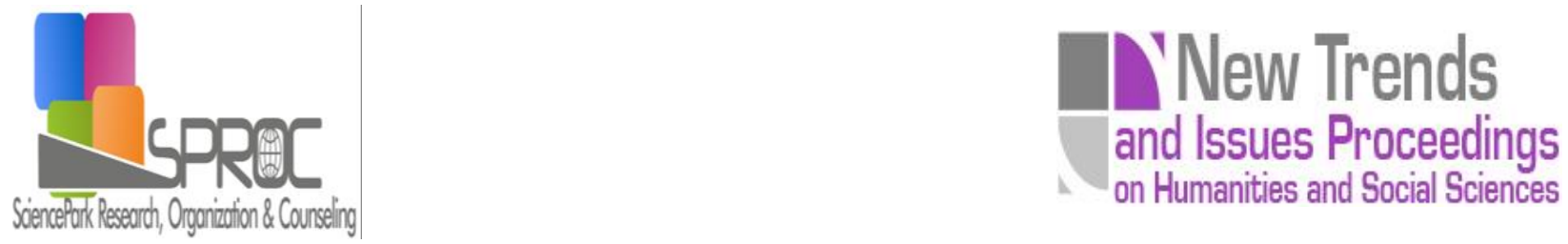

S

www.prosoc.eu

\title{
New Regression Equations for Estimating the Maximal Oxygen Uptake of College of Physical Education and Sports Students in Turkey
}

Mehmet Fatih Akay *

Fatih Abut ${ }^{\text {b }}$

Kiymet Kaya ${ }^{c}$

Ebru Cetin ${ }^{\mathrm{d}}$

Imdat Yarim

Suggested Citation:

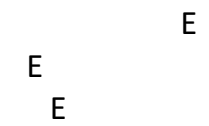

E

E

S

Abstract

$\mathrm{S}$ 


\section{$\longrightarrow$}

1. Introduction 
2. Dataset Generation

S

Table 1.Descriptive statistics of the dataset.

\begin{tabular}{lllll}
\hline Predictor Variables & Sample & & Validation Sample & Range \\
& Mean & Range & Mean & Rean \\
\hline
\end{tabular}

$\mathrm{S}$

3. Results and Discussion 


$$
\begin{gathered}
S E E=\sqrt{\frac{\sum\left(Y-Y^{\prime}\right)^{2}}{N}} \\
R=\sqrt{1-\frac{\sum\left(Y-Y^{\prime}\right)^{2}}{\sum(Y-\bar{Y})^{2}}} \\
Y \quad Y^{s}
\end{gathered}
$$

Table 2.SEE and $R$ values of $\mathrm{VO}_{2}$ max prediction models.

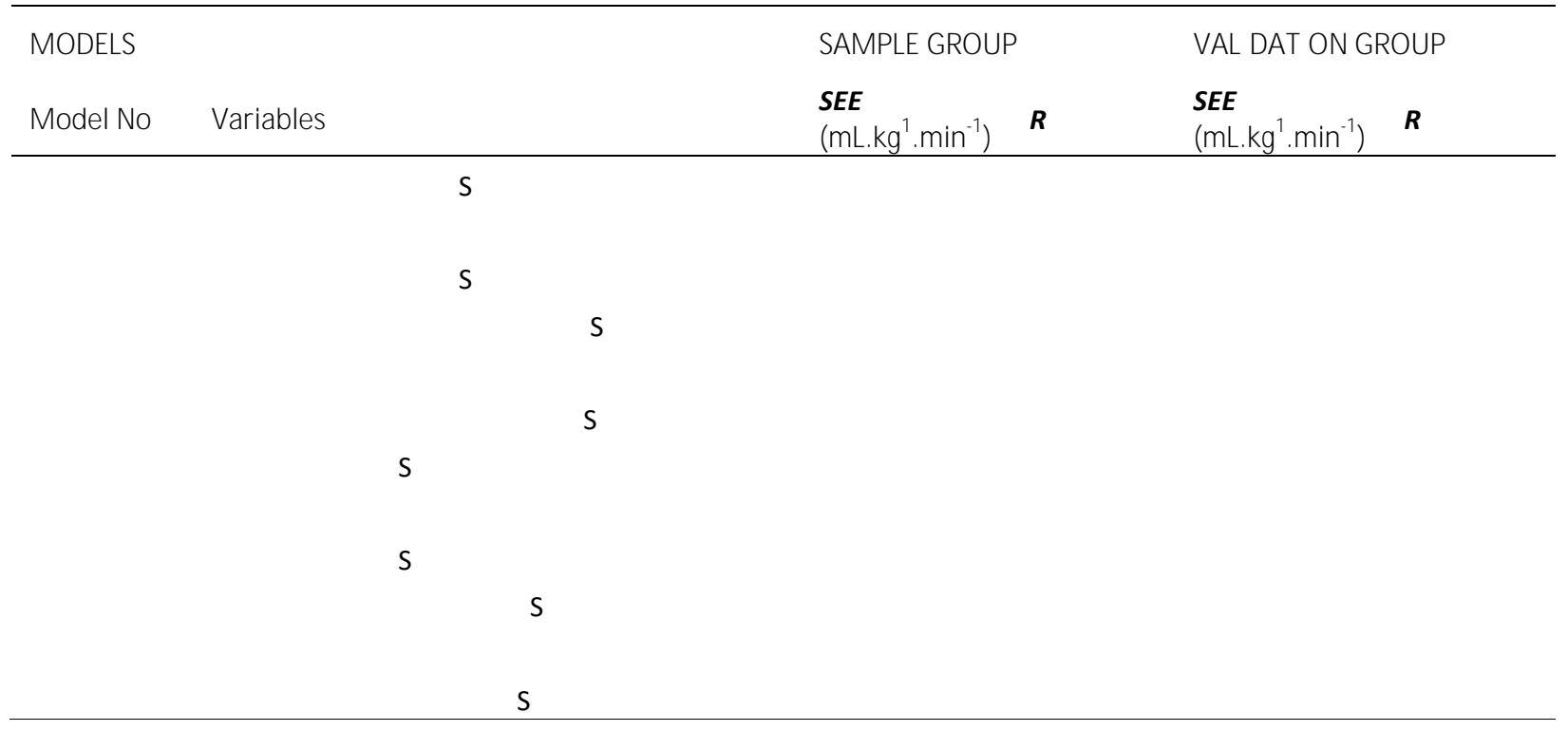




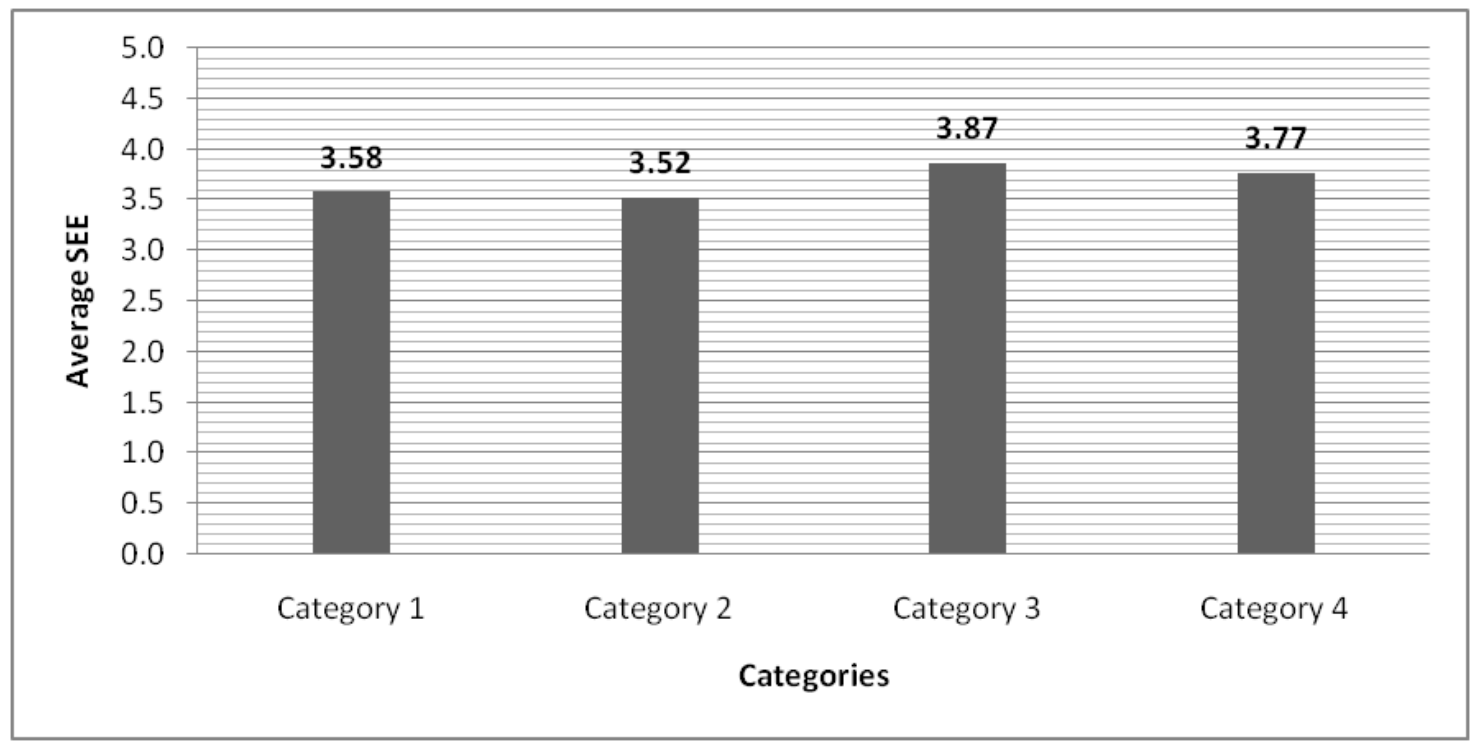

Figure1.Average SEE's of the prediction models for the sample group.

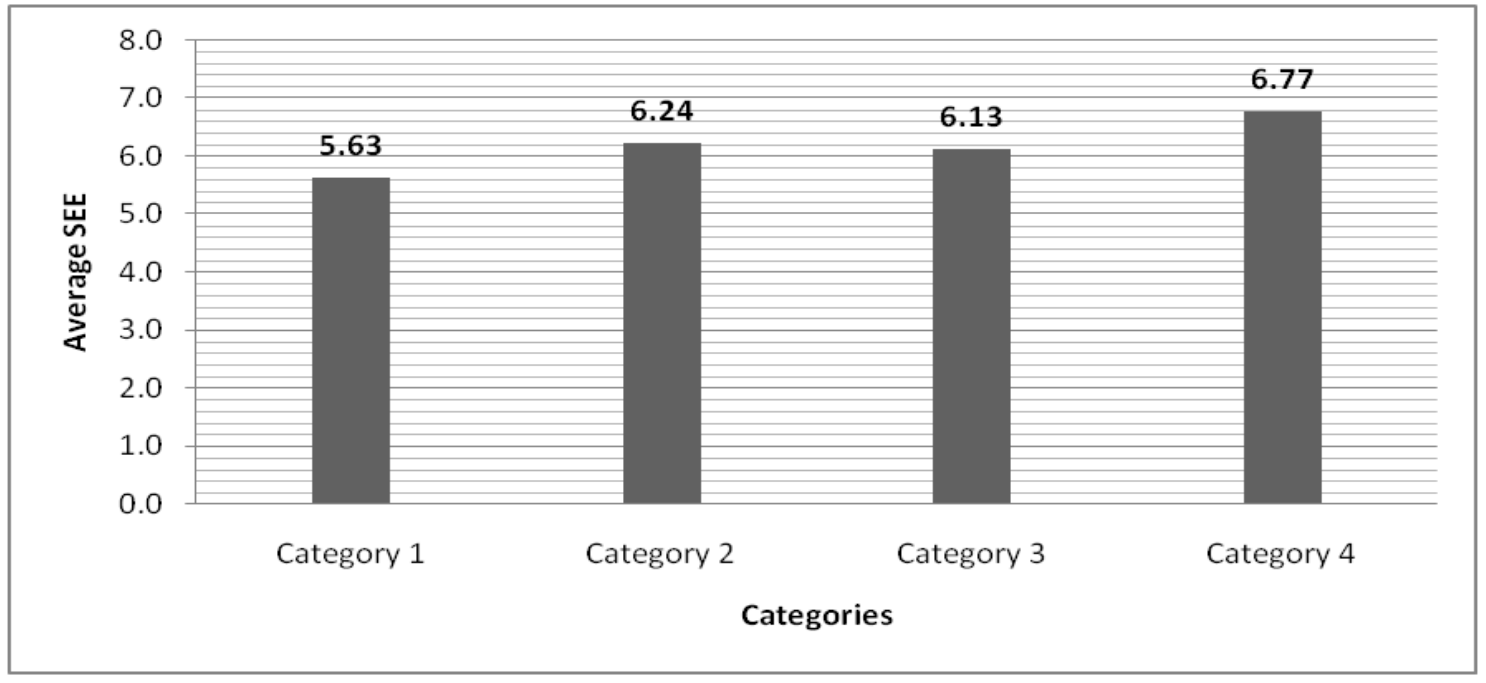

Figure 2.Average SEE's of the prediction models for the validation group 
S

S

S

-

4. Conclusion

S

S

References

S

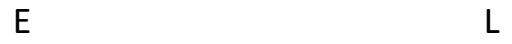

E

E E

E L

L
S

S

S

S
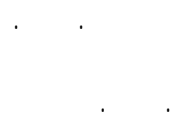

S

S

S

E 
S

$\longrightarrow$

L

L S

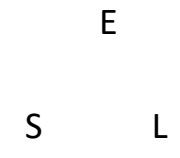

S

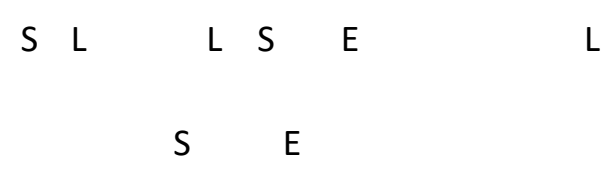

$\begin{array}{lllll}L & L & S & \mathrm{~L}\end{array}$

$\mathrm{S}$

S

$\mathrm{S}$

S

L

E

L E 